\title{
Second Left Ventricular Aneurysm Newly Developed in a Patient With Untreated Cardiac Sarcoidosis
}

\author{
Takahiro Sato, MD; Hideaki Kanzaki, MD; Yoshio Ishida, MD; Makoto Amaki, MD; \\ Takahiro Ohara, MD; Takuya Hasegawa, MD; Kazuhiko Hashimura, MD; \\ Satoshi Nakatani, MD; Naoaki Yamada, MD; Yoshihiko Ikeda, MD; \\ Hatsue Ueda-Ishibashi, MD; Masafumi Kitakaze, MD
}

Figure 1. Cardiac cine magnetic resonance imaging shows 2 aneurysms at the middle anterior and basal posterior segments (arrows) in the left ventricular long-axis view.

A 53-year-old man was referred to our hospital because of developing exertional dyspnea (NYHA functional class II). His electrocardiogram (ECG) had already shown a negative $\mathrm{T}$ wave in leads II, III, $\mathrm{aV}_{\mathrm{F}}$, and $\mathrm{V}_{1-3}$ at a physical checkup 2 years before. In cardiac catheterization, left ventriculography had revealed a ventricular aneurysm at the basal posterior segment despite normal coronary arteries. Because no symptoms were apparent, however, a wait-and-see approach had been undertaken for 2 years.

On admission to our hospital, an ECG showed a negative $\mathrm{T}$ wave in leads II, III, $\mathrm{aV}_{\mathrm{F}}$, and $\mathrm{V}_{1-4}$. Cardiac cine magnetic resonance imaging (MRI) revealed that there was a second aneurysm that was newly developed at the middle anterior segment, in addition to the first aneurysm (Figure 1). An MRI late gadolinium enhancement was present in both of the aneurysms and in the enlarged right ventricle transmurally, whereas a T2-weighted MRI showed normal myocardial signal intensity. Fluorine-18 fluorodeoxyglucose ( $\left.{ }^{18} \mathrm{~F}-\mathrm{FDG}\right)$ positron emission tomography (PET) images obtained after a period of $12 \mathrm{~h}$ of fasting showed high FDG accumulation in the basal and apical regions of the left ventricle corresponding to the aneurysms and the hilar lymph nodes (Figure 2). We suspected cardiac sarcoidosis because of the

Received February 16, 2010; revised manuscript received July 10, 2010; accepted July 12, 2010; released online September 28, 2010 Time for primary review: 14 days

Department of Cardiovascular Medicine, Heart Failure Division (T.S., H.K., M.A., T.O., T.H., K.H., S.N., M.K.), Department of Radiology and Nuclear Medicine (Y. Ishida, N.Y.), and Department of Pathology (Y. Ikeda, H.U.-I.), National Cerebral and Cardiovascular Center, Suita, Japan

Mailing address: Hideaki Kanzaki, MD, Department of Cardiovascular Medicine, Heart Failure Division, National Cerebral and Cardiovascular Center, 5-7-1 Fujishiro-dai, Suita 565-8565, Japan. E-mail: kanzakih@ @sp.ncvc.go.jp

ISSN-1346-9843 doi:10.1253/circj.CJ-10-0139

All rights are reserved to the Japanese Circulation Society. For permissions, please e-mail: cj@j-circ.or.jp 

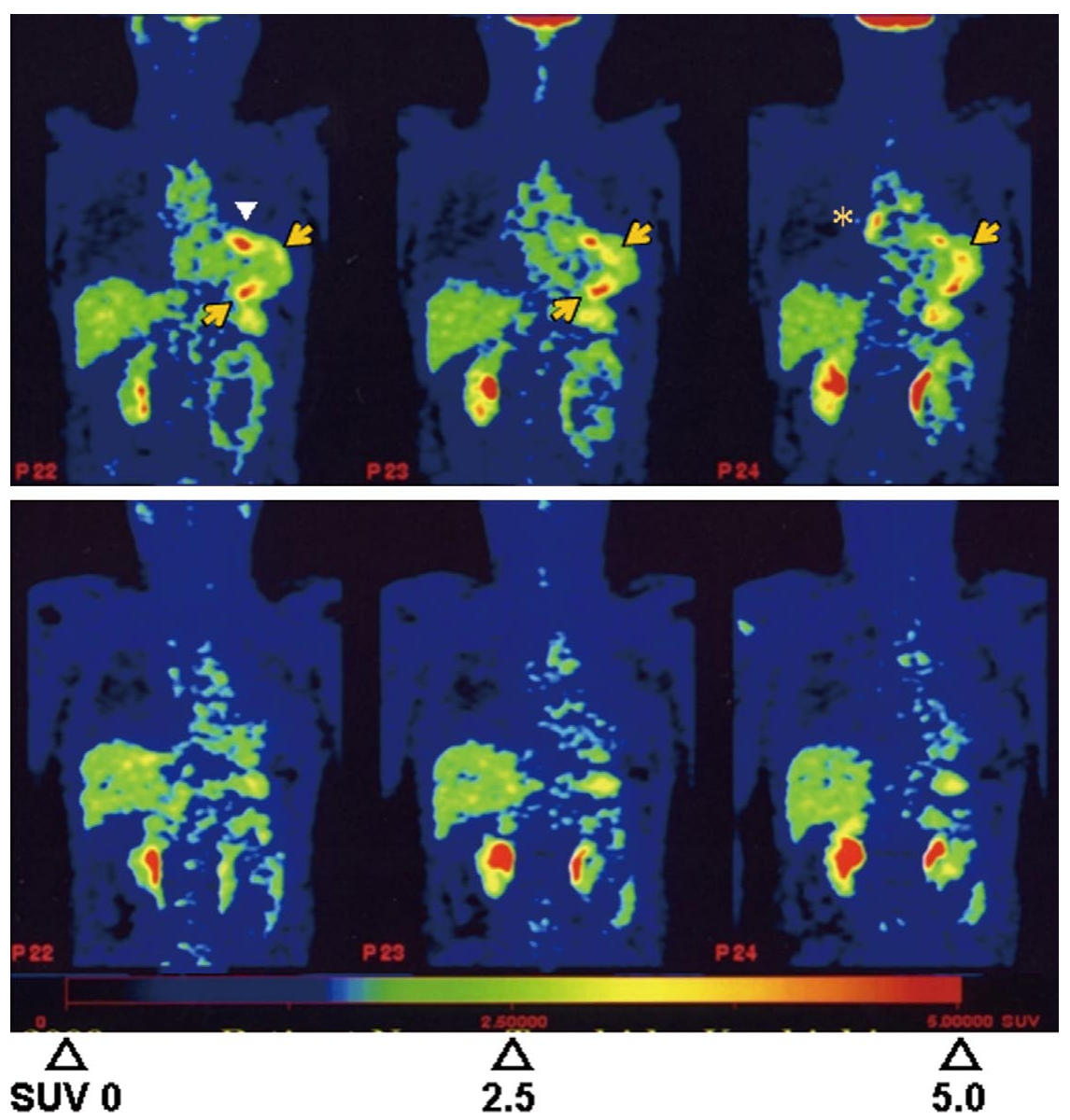

Figure 2. ${ }^{18} \mathrm{~F}-\mathrm{FDG}$ PET shows regionally enhanced accumulation in the left ventricle (maximum standardized uptake value $[S U V \max ]=4.4, \nabla$ ), the basal posterior and mid anterior segments corresponding to the aneurysms (arrows), and the right hilar focal uptake ( $\left(\mathrm{s}_{\mathrm{s}}\right.$ ) before steroid therapy (Upper row) in the coronal view. The marked reduction of the accumulation (SUVmax= 0.5) after steroid therapy is exhibited (Lower row). ${ }^{18} \mathrm{~F}-\mathrm{FDG} \mathrm{PET}$, fluorine-18 fluorodeoxyglucose positron emission tomography.

regional myocardial delayed-enhancement without reference to coronary distribution in $\mathrm{MRI}^{1,2}$ and uptake in ${ }^{18} \mathrm{~F}-\mathrm{FDG}$ PET, ${ }^{3}$ and the patient underwent cardiac catheterization. No significant stenosis in the coronary artery was detected and left ventriculography revealed the 2 aneurysms and a severely impaired contraction with an ejection fraction of $25 \%$. An endomyocardial biopsy was performed and it showed a noncaseous epithelioid granuloma with giant cells, supporting the diagnosis of cardiac sarcoidosis.

The treatment was started with oral predonisolone of $30 \mathrm{mg} /$ day, and 4 weeks later, ${ }^{18} \mathrm{~F}$-FDG PET imaging showed marked attenuation of the uptake (Figure 2), but MRI showed less changes in the aneurysms and delayed enhancement 1 year later. No recurrence has been detected by ${ }^{18} \mathrm{~F}-\mathrm{FDG}$ PET in the subsequent 2 years with a reduced dose of predonisolone. Cardiac sarcoidosis can be an uncommon cause of cardiomyopathy, ${ }^{4,5}$ but the existence of a type of cardiac sarcoidosis, which is noticed first by a ventricular aneurysm, should be more widely known. MRI late gadolinium enhancement has been reported to be useful to identify myocardial fibrosis in non-ischemic cardiomyopathy. ${ }^{6,7}$ The combination of ${ }^{18} \mathrm{~F}-\mathrm{FDG}$ PET and MRI is recommended to detect cardiac involvement of sarcoidosis.

\section{References}

1. Smedema JP, Snoep G, van Kroonenburgh MP, van Geuns RJ, Dassen WR, Gorgels AP, et al. Evaluation of the accuracy of gadolinium-enhanced cardiovascular magnetic resonance in the diagnosis of cardiac sarcoidosis. J Am Coll Cardiol 2005; 45: 16831690.

2. Ishida M, Kato S, Sakuma H. Cardiac MRI in ischemic heart disease. Circ J 2009; 73: 1577-1588.

3. Ishimaru S, Tsujino I, Takei T, Tsukamoto E, Sakaue S, Kamigaki $\mathrm{M}$, et al. Focal uptake on 18F-fluoro-2-deoxyglucose positron emission tomography images indicates cardiac involvement of sarcoidosis. Eur Heart J 2005; 26: 1538 - 1543.

4. Terasaki F, Ukimura A, Tsukada B, Fujita S, Katashima T, Otsuka $\mathrm{K}$, et al. Enhanced expression of type 1 helper T-cell cytokines in the myocardium of active cardiac sarcoidosis. Circ $J$ 2008; 72: 1303-1307.

5. Kimura A. Molecular etiology and pathogenesis of hereditary cardiomyopathy. Circ J 2008; 72(Suppl A): A-38-A-48.

6. Oikawa M, Ota H, Takaya N, Miller Z, Hatsukami TS, Yuan C. Carotid magnetic resonance imaging: A window to study atherosclerosis and identify high-risk plaques. Circ J 2009; 73: 17651773.

7. Mahrholdt H, Wagner A, Judd RM, Sechtem U, Kim RJ. Delayed enhancement cardiovascular magnetic resonance assessment of non-ischaemic cardiomyopathies. Eur Heart J 2005; 26: 1461 1474. 